\title{
Retrieval of forest leaf functional traits from HySpex imagery using radiative transfer models and continuous wavelet analysis
}

\author{
Abebe Mohammed Ali ${ }^{\mathrm{a}, \mathrm{b}, *}$, Andrew K. Skidmore ${ }^{\mathrm{a}}$, Roshanak Darvishzadeh ${ }^{\mathrm{a}}$, Iris van Duren ${ }^{\mathrm{a}}$, \\ Stefanie Holzwarth ${ }^{\mathrm{c}}$, Joerg Mueller ${ }^{\mathrm{d}}$ \\ ${ }^{a}$ Faculty of Geo-Information Science and Earth Observation (ITC), University of Twente, P.O. Box 217, 7500 AE Enschede, The Netherlands \\ ${ }^{\mathrm{b}}$ Department of Geography and Environmental Studies, Wollo University, P.O. Box 1145, Dessie, Ethiopia \\ ${ }^{\mathrm{C}}$ German Aerospace Center (DLR), German Remote Sensing Data Center (DFD) Oberpfaffenhofen, 82234 Wessling, Germany \\ ${ }^{\mathrm{d}}$ Bavarian Forest National Park, 94481 Grafenau, Germany
}

\section{A R T I C L E I N F O}

\section{Article history:}

Received 18 November 2015

Received in revised form 28 July 2016

Accepted 26 September 2016

\section{Keywords:}

Continuous wavelet analysis

INFORM

LDMC

SLA

Leaf traits

\begin{abstract}
A B S T R A C T
Quantification of vegetation properties plays an important role in the assessment of ecosystem functions with leaf dry mater content (LDMC) and specific leaf area (SLA) being two key functional traits. For the first time, these two leaf traits have been estimated from the airborne images (HySpex) using the INFORM radiative transfer model and Continuous Wavelet Analysis (CWA). Ground truth data, were collected for 33 sample plots during a field campaign in July 2013 in the Bavarian Forest National Park, Germany, concurrent with the hyperspectral overflight. The INFORM model was used to simulate the canopy reflectance of the test site and the simulated spectra were transformed to wavelet features by applying CWA. Next, the top 1\% strongly correlated wavelet features with the LDMC and SLA were used to develop predictive (regression) models. The two leaf traits were then retrieved using the CWA transformed HySpex imagery and the predictive models. The results were validated using $R^{2}$ and the RMSE of the estimated and measured variables.

Our results revealed strong correlations between six wavelet features and LDMC, as well as between four wavelet features and SLA. The wavelet features at $1741 \mathrm{~nm}$ (scale 5) and $2281 \mathrm{~nm}$ (scale 4) were the two most strongly correlated with LDMC and SLA respectively. The combination of all the identified wavelet features for LDMC yielded the most accurate prediction $\left(R^{2}=0.59\right.$ and RMSE $\left.=4.39 \%\right)$. However, for SLA the most accurate prediction was obtained from the single most correlated feature: $2281 \mathrm{~nm}$, scale $4\left(R^{2}=0.85\right.$ and RMSE $\left.=4.90\right)$. Our results demonstrate the applicability of Continuous Wavelet Analysis (CWA) when inverting radiative transfer models, for accurate mapping of forest leaf functional traits.
\end{abstract}

(c) 2016 International Society for Photogrammetry and Remote Sensing, Inc. (ISPRS). Published by Elsevier B.V. All rights reserved.

\section{Introduction}

Two key plant functional biodiversity traits are leaf dry matter content (LDMC) (which is the ratio of leaf dry mass to leaf fresh mass), and specific leaf area (SLA) (which is the ratio of leaf area to leaf dry mass). LDMC is a proxy for relative growth rate and carbon assimilation, and is an important predictor of a plant's location on an axis of resource capture, usage and availability (Wilson et al., 1999). SLA (also referred as leaf mass per unit area, specific leaf mass, or leaf specific mass), links plant carbon and water cycles

\footnotetext{
* Corresponding author at: Department of Geography and Environmental Studies, Wollo University, P.O. Box 1145, Dessie, Ethiopia.

E-mail address: abebemohammed@yahoo.co.uk (A.M. Ali).
}

(Pierce et al., 1994), provides information on spatial variation of photosynthetic capacity and leaf nitrogen content, and is indicative of plant physiological processes such as light capture, growth rates, and life strategies of plants (Pierce et al., 1994). A worldwide foliar dataset indicates that $82 \%$ of all variation in photosynthetic capacity can be explained by SLA and nitrogen (Wright et al., 2004).

The two traits are inversely correlated and are also used to estimate other traits and ecological indicators, such as leaf thickness, leaf life span (Shipley, 2002; Vile et al., 2005; Marenco et al., 2009), relative growth rate (Shipley, 2006), and soil fertility (Hodgson et al., 2011). Generally, the quantitative information and spatial distribution of LDMC and SLA improve our understanding and capacity to investigate community structure and ecosystem functioning (Mouchet et al., 2010; Lavorel et al., 2011). 
However; these traits are currently quantified through laborintensive methods of field sampling. Consequently, ecological understanding of trait variation across extended spatial and temporal scales is lacking (Messier et al., 2010).

Remote sensing, as a relatively fast and efficient approach for estimating LDMC and SLA across a wide range of spatial and temporal scales, has so far received little attention for quantification of these traits. Only a few studies have attempted to estimate SLA using remote sensing data. Lymburner et al. (2000) tested vegetation indices derived from the green, red, NIR, and MIR bands of Landsat TM data and found a correlation between these bands and canopy average SLA. Vegetation indices have been developed for estimation of leaf mass per area in Fontainebleau and Fougères broadleaf forests in France by le Maire et al. (2008) and Feret et al. (2011). Until recently, however, none of the remote sensing techniques have been tested for direct estimation of LDMC. A leaf scale study using PROSPECT model inversion reported the potential of remote sensing for quantifying LDMC and SLA (Ali et al., 2016b). Another study by Cheng et al. (2014b) demonstrated the potential of wavelet analysis to retrieve leaf mass area (LMA) from sets of simulated and measured leaves reflectance however, this study was conducted at leaf scale and needs further examination when upscaling to canopy level.

A number of statistical methods have been widely applied for retrieval of biophysical and biochemical parameters of vegetation from remote sensing data (e.g. le Maire et al., 2008; Darvishzadeh et al., 2009). Nevertheless these methods have been criticized for being site-specific and lacking generalization (Darvishzadeh et al., 2011). Inversion of Radiative Transfer Models (RTM) has been suggested as an alternative approach for parameter retrieval from remote sensing data, but RTMs still require local information such as cover type in order to be accurately upscaled (Si et al., 2012). RTMs allow creation of simulated training databases covering a wide range of situations and configurations to which inversion algorithms can be applied to retrieve parameters from remote sensing data. A wide variety of studies have evaluated the performance of radiative transfer model inversion techniques to estimate vegetation biophysical and biochemical parameters such as chlorophyll (Darvishzadeh et al., 2008; Darvishzadeh et al., 2012; Lv et al., 2014; Wang et al., 2014), LAI (Meroni et al., 2004; Dini et al., 2006; Darvishzadeh et al., 2008; Yang et al., 2011; Cho et al., 2014), biomass and others vegetation characteristics (Kazemipour et al., 2010; Dorigo, 2012). A recent comparative analysis by Atzberger et al. (2015) showed the potential and drawbacks of different retrieval methods for mapping grassland leaf area index. Their study indicated the robustness and higher accuracy of RTMs inversion approaches over statistical methods.

However, because of redundancy and multi-collinearly in hyperspectral data (Blackburn, 2007a), RTM inversions are often applied on selected bands sensitive to a given vegetation variable. Although a subset of spectral bands proved to be a stable and accurate predictor for vegetation parameters (Weiss et al., 2000), no general criteria have been formulated for the selection of bands (Banskota et al., 2013b). Wavelet transformation seems to be a promising alternative technique for selecting the most informative features from hyperspectral data.

Wavelet analysis enables spectral data to be transformed into a new representation by decomposing the original spectra into various scales (frequencies). Subsequently, the correlation between the concentration of parameters and the wavelet scales can identify the most sensitive spectral feature for predicting a given parameter. Previous studies have investigated the potential of wavelet analysis for estimating leaf parameters from leaf spectra measured in the laboratory and simulated data using RTMs (Jingcheng et al., 2011; Cheng et al., 2012; Ullah et al., 2012a; Zhang et al., 2012; Cheng et al., 2014a). However, the applicability of wavelet analysis at canopy level using canopy spectra obtained from airborne and spaceborne hyperspectral data has received little attention. Further study is needed to understand how wavelet analysis can be applied to airborne or spaceborne image data for retrieving vegetation parameters. This is because canopy spectral reflectance obtained from these images is more complex than the spectral reflectance of individual leaves, due to factors such as sensor noise, soil background, shadow, canopy structural variation, non-photosynthetic vegetation, and solar and viewing geometry (Ustin et al., 2009; Wolf et al., 2010; Ollinger, 2011).

There are two forms of wavelet transformation: discrete and continuous. Discrete Wavelet Analysis (DWA) has the potential to avoid redundancy; it transforms and uses the most informative part of the input data but it is difficult to assign wavelet features to a specific band because of scale variability during the transformation. Continuous wavelet analysis (CWA) is more timeconsuming and has data redundancy limitations. Nevertheless, CWA has evolved as a promising tool for quantitatively analyzing vegetation parameters from hyperspectral remote sensing data (e.g. Blackburn, 2007b; Cheng et al., 2014a). It allows band-byband interpretation of very subtle spectral information. CWA can operate at various scales, starting from the original signal and going up to maximum scales defined by the user. Our study applied continuous wavelet transformation, because each scale component from CWA is directly comparable to the input reflectance spectrum on a band-by-band basis and the results are easily interpreted and can be related to wavelengths with minimal uncertainty (Cheng et al., 2011).

Banskota et al. (2013a, 2013b) applied DWA to estimate forest leaf area index (LAI) in temperate forests from AVIRIS (airborne visible/infrared imaging spectrometer) data using both statistical and RTM inversion techniques. In another study, CWA was found to perform well at detecting diurnal and seasonal variation in the canopy water content of nut tree orchards from airborne spectral data on the basis of canopy water content measurements in the field and concurrent imagery from the AVIRIS instrument (Cheng et al. (2014a).

Our study aimed at quantifying LDMC and specific leaf area (SLA) for a mountain forest using HySpex airborne hyperspectral data through the INFORM radiative transform model. The model inversion was undertaken via an optimized predictive model constructed from Continuous wavelet analysis (CWA) coefficients. We posited that there will be an optimal spectral wavelength domain for use in CWA for quantifying the two traits. Our three aims were to (1) identify spectral bands sensitive to LDMC and SLA using HySpex airborne data; (2) assess the performance of predictive models constructed from the combination of wavelet features derived from different spectral wavelength domains for LDMC and SLA retrieval, and (3) map the LDMC and SLA of the study area using HySpex imagery in conjunction with the best performing predictive models.

\section{Methodology}

\subsection{Analytical framework}

The overall procedures followed in this study are presented in Fig. 1. In order to retrieve and map the spatial distribution of the two leaf traits (LDMC and SLA) from HySpex imagery, three sets of data have been utilized. (1) A wide variety of simulated canopy spectra with its corresponding LDMC and SLA values (calibration dataset), (2) Ground truth data in 33 sample plots (validation dataset), which contains canopy spectra extracted from HySpex images with their corresponding LDMC and SLA values collected in the field, and (3) HySpex images of the study area. The INFORM model 


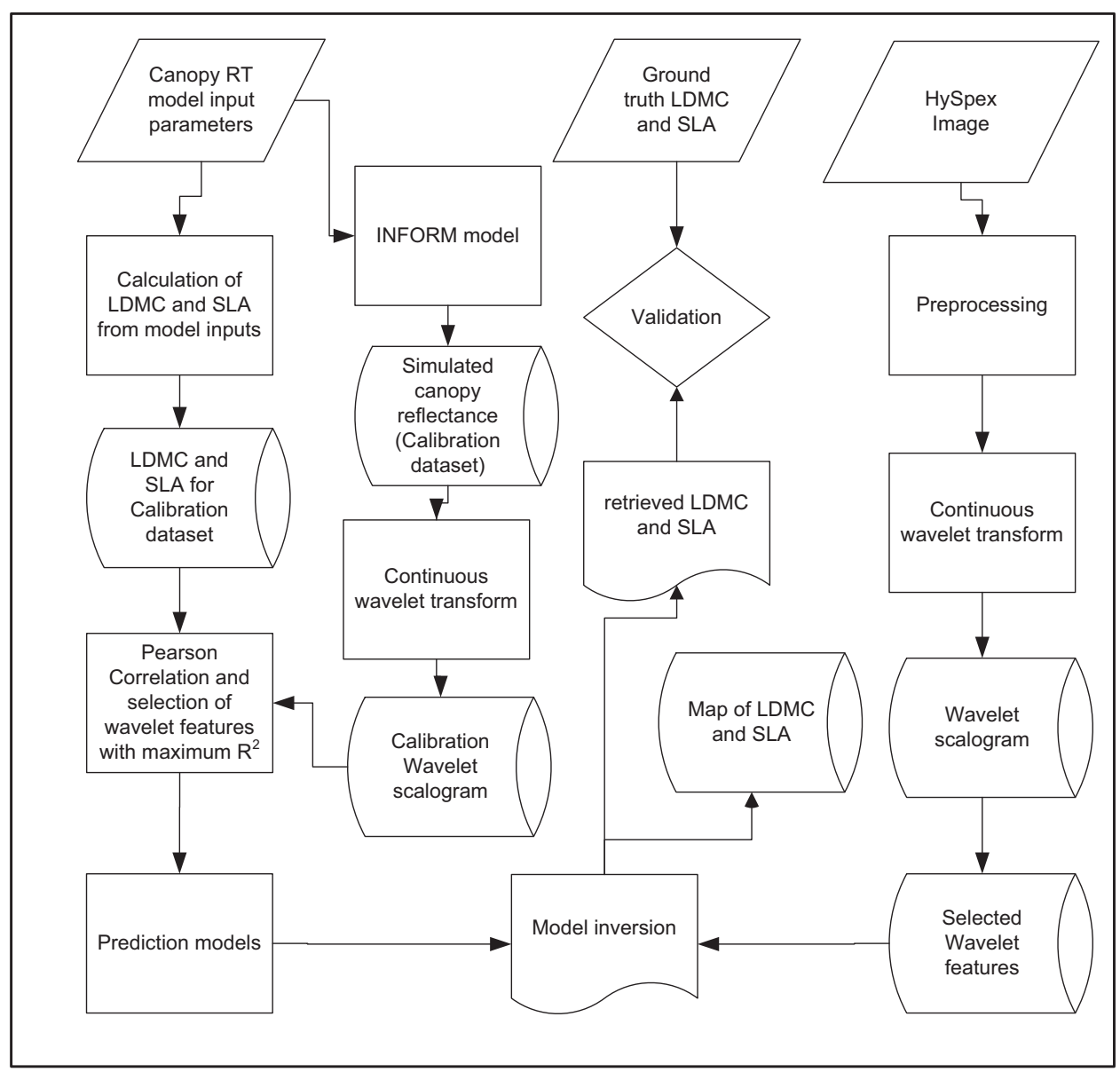

Fig. 1. Analytical framework of the methods applied for the retrieval of LDMC and SLA from HySpex hyperspectral image.

was parametrized and run in its forward mode to build a calibration dataset of canopy spectra with their corresponding model input parameters. The HySpex images were atmospherically corrected, mosaicked and pre-processed. Then, wavelet transformation was applied to both the INFORM simulated spectra and the HySpex image. Spectral features strongly correlated to the two leaf traits concentration have been identified by computing and ranking the Pearson correlation calculated for the calibration dataset. The top $1 \%$ of strongly correlated wavelet features were used to develop prediction models. Next, the developed prediction models were applied on the identified wavelet features of the HySpex data to retrieve and map the spatial distribution of the two traits in the study site. Finally accuracy assessment have been conducted using the 33 sample plots spectra extracted from HySpex imagery and their corresponding ground truth LDMC and SLA values (validation dataset). The details of the methodology are presented in the following subsections.

\subsection{Test site and field data}

The test site for this study was the mixed mountain forest of the Bavarian Forest National Park. The park is located in south-eastern Germany along the border with the Czech Republic $\left(49^{\circ} 3^{\prime} 19^{\prime \prime} \mathrm{N}\right.$, $13^{\circ} 12^{\prime} 9^{\prime \prime} \mathrm{E}$ ) (Fig. 2). Elevation of the test site varies from $600 \mathrm{~m}$ to $1473 \mathrm{~m}$ above sea level. The climate of the region is temperate, with high annual precipitation (1200-1800 mm) and low average annual temperature $\left(3-6^{\circ} \mathrm{C}\right)$. Heavy snow cover is characteristic of the area in winter. Brown soils are the predominant soil type at lower altitude (below $900 \mathrm{~m}$ asl) whereas at high altitude (above $900 \mathrm{~m}$ a.s.l) brown soils and brown podzolic soil predominate. The soils in the area are naturally acidic and low in nutrient content (Heurich et al., 2010). The natural forest ecosystems of the Bavarian Forest National Park vary with altitude: there are alluvial spruce forests in the valleys, mixed mountain forests on the hillsides and mountain spruce forests in the high areas. The dominant tree species include European beech (Fagus sylvatica), Norway spruce (Picea abies) and Fir (Abies alba). In the mixed mountain forests Sycamore maple (Acer pseudoplatanus L.), Mountain ash (Sorbus aucuparia L.) and Goat willow (Salix caprea) are also found (Heurich and Neufanger, 2005). Due to heavy disturbance by bark beetles and wind storms in recent decades the forest structure in the park is very heterogeneous (Lehnert et al., 2013).

A field campaign was conducted during summer 2013 to collect ground truth data from 33 plots. The test site was stratified into broadleaf, conifers and mixed forest stands. Given the heterogeneity of the forest and the time and cost constraints, we randomly selected 33 plots from the three main forest class strata resulting in 10 samples in broadleaf, nine in conifer and 14 in mixed stands. Each plot was square, with sides $30 \mathrm{~m}$ long. In all 33 sample plots, forest structural variables such as LAI, stem density (SD), canopy closure $(\mathrm{CC})$, crown diameter $(\mathrm{CD})$, and stand height $(\mathrm{SH})$ were measured. The LAI of each plot was measured using an LAI_2000 plant canopy analyzer (LI-COR, Lincoln, NE, USA) and also computed from hemispherical photographs taken in each plot by using CIMES-FISHEYE software for validation purposes. The SD was recorded as number of trees per hectare based on the number of trees in each plot. CC was estimated by averaging five observations in a plot using a spherical crown densitometer (Forestry suppliers, Jackson, MS, USA). Since the stratification of forest stands into deciduous, mixed and conifer had highly minimized the variability 


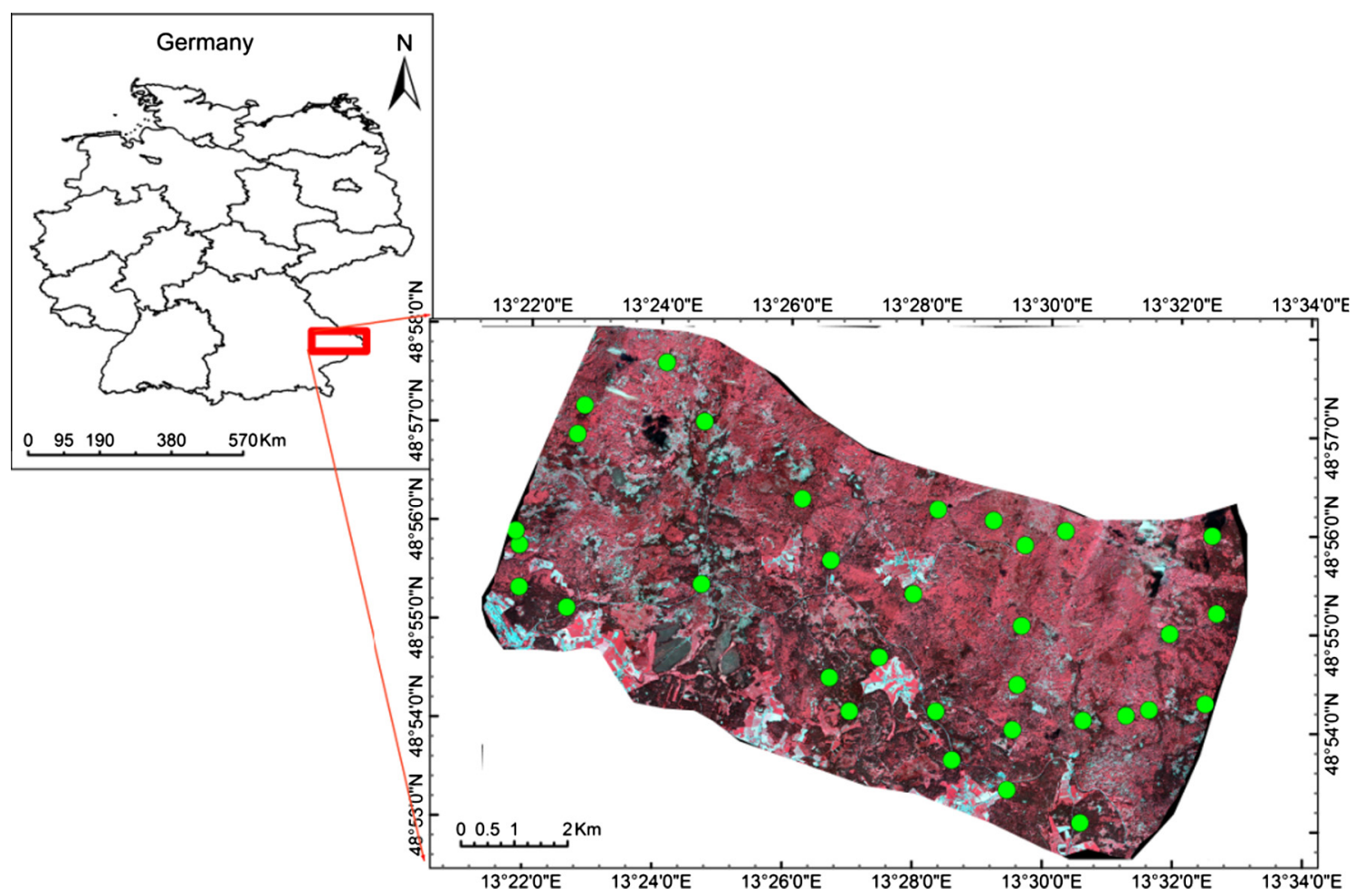

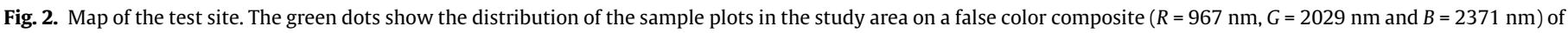
the HySpex image. (For interpretation of the references to colour in this figure legend, the reader is referred to the web version of this article.)

of canopy structural variables within each stratum, trees are evenly distributed and there is no as such significant variation in tree height and crown diameter per plot/forest stand. Therefore, CD and $\mathrm{SH}$ were calculated from the mean crown diameter and mean height of five trees randomly selected in each plot. The $C D$ of each tree was determined by averaging two perpendicular projected distances on the ground. The total height of each tree was estimated by using a Nikon Forestry 550 laser rangefinder (Nikon Vision, Tokyo, Shinagawa-ku, Japan).

In each plot, leaf samples were collected from mature sunlit leaves at the top of the canopy of 3-5 trees, using a crossbow, and their characteristics were measured $(n=130)$. Leaf area of broadleaf leaf samples was measured using the LI-3000C portable leaf area meter (LI-COR, Lincoln, Nebraska, USA). The surface of sample conifer needles was scanned using an HP double lamp desktop scanner at a resolution of $1200 \mathrm{dpi}$; the needle projections were computed from the grayscale images using ImageJ open source image processing software (National Institute of Mental Health, Bethesda, Maryland, USA). For details on the leaf samples' physical variable measurements, see (Ali et al., 2016b). The collected leaf samples were transported to the laboratory for further analysis. All samples were oven dried at $65^{\circ} \mathrm{C}$ for $48 \mathrm{~h}$ and then LDMC, SLA, leaf mass per leaf area $\left(C_{m}\right)$ and leaf water content $\left(C_{w}\right)$ were computed based on fresh and oven-dried leaf mass and leaf areas. For mixed plots, the average values for LDMC, SLA $C_{m}, C_{w}$ and leaf structural parameter ( $\mathrm{N}$ ) were based on crown biomass proportion of each species in a given plot.

The variables measured in the field are summarized in Table 1. The leaf structural parameter- $\mathrm{N}$ was retrieved by inverting the PROSPECT model using simulation at three wavelengths (see Ali et al., 2016b). During the field campaign, the spectral reflectance of leaf samples and understory vegetation and ecosystem elements on the forest floor such as bark, litter, mosses and lichens was also measured by using the ASD field spectroradiometer coupled to a high intensity contact probe and integrating sphere.

\subsection{Image acquisition and pre-processing}

HySpex is a new airborne hyperspectral sensor developed by the Norwegian Norsk Elektro Optikk (NEO) company. It comprises two imaging spectrometers with spectral ranges of $400-1000 \mathrm{~nm}$ and $1000-2500 \mathrm{~nm}$ and up to 416 spectral channels. It is supported by a precise navigation system for georeferencing and correction of geometric errors. Both of its sensors operate in a push-broom scanning mode with an angular recording image width of $15^{\circ}$. Its field of view can be doubled to $30^{\circ}$ using a field expander lens. It records radiance data in contiguous bands at a spectral resolution of $3.7 \mathrm{~nm}$ for $400-992 \mathrm{~nm}$ spectral range (sensor 1 ) and $6 \mathrm{~nm}$ for 968-2498 spectral range (sensor 2). Its spatial resolution is $1.6 \mathrm{~m}$ for sensor 1 and $3.4 \mathrm{~m}$ for sensor 2 .

The HySpex instrument was flown over the test site onboard a Cessna 208B Grand Caravan at an average altitude of $3010 \mathrm{~m}$ above sea level on July 222013 between 9:00 and 11:15 local time. A total of 19 flights were made to cover the test site. The HySpex image data were supplied by the DLR team after atmospheric correction performed with the ATCOR4 model, orthorectified and georeferenced using standard aircraft in-flight information such as attitude and flight path data in combination with a digital terrain model (DEM). The view angle effects between the 19 flight line images were removed using empirical view-angle correction technique proposed by Kennedy et al. (1997) (Fig. 2). As only the spectral bands in the SWIR were utilized in this study, only the images from sensor 2 of HySpex were mosaicked.

To prepare the HySpex data for further analysis, the mosaicked image reflectance was spatially resampled over a $9 \times 9$ pixel window, which most closely approximates the size of the sample plots (approximately $30 \mathrm{~m} \times 30 \mathrm{~m}$ ) using the nearest neighbor resampling technique. Then, a Savitzky-Golay filter was applied to correct for random and systematic noise. Finally, the average reflectance of the sample plots was extracted and used for evaluation (hereafter referred as the measured or validation dataset). The 
Table 1

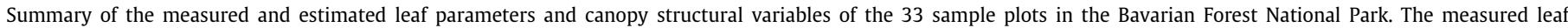

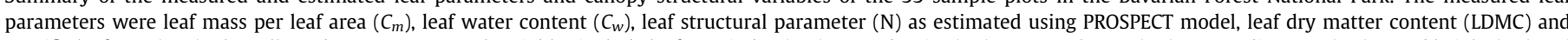

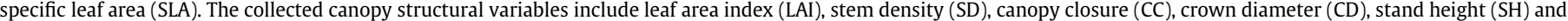
average leaf angle (ALA).

\begin{tabular}{|c|c|c|c|c|c|c|c|c|c|c|c|}
\hline Parameter & $C_{m}\left(\mathrm{~g} / \mathrm{cm}^{2}\right)$ & $C_{w}\left(\mathrm{~g} / \mathrm{cm}^{2}\right)$ & $\mathrm{N}$ & LDMC (g/g) & SLA $\left(\mathrm{cm}^{2} / \mathrm{g}\right)$ & LAI $\left(\mathrm{m}^{2} / \mathrm{m}^{2}\right)$ & SD (n/ha) & CC (\%) & $\mathrm{CD}(\mathrm{m})$ & $\mathrm{SH}(\mathrm{m})$ & ALA (deg) \\
\hline Minimum & 0.0061 & 0.0071 & 1.36 & 0.3999 & 43.45 & 2.42 & 222 & 38 & 2.91 & 12.26 & 40 \\
\hline Maximum & 0.0292 & 0.0309 & 1.93 & 0.5075 & 165.64 & 6.18 & 1722 & 91 & 10.55 & 27.36 & 60 \\
\hline Mean & 0.0147 & 0.0178 & 1.58 & 0.4534 & 89.38 & 4.3 & 778.4 & 75.19 & 5.67 & 20.23 & 50 \\
\hline St. dev. & 0.0059 & 0.0071 & 0.16 & 0.0254 & 37.72 & 0.81 & 405.5 & 5.33 & 1.56 & 4.52 & 9.96 \\
\hline
\end{tabular}

noisy bands in the water absorption region (1345-1450 $\mathrm{nm}$ and $1790-1980 \mathrm{~nm}$ ) and bands from 2450 to $2498 \mathrm{~nm}$ were assigned zero values. This left a total of 203 bands with valid reflectance values.

\subsection{RTM parameterization and forest reflectance simulation}

To simulate the spectral property of the test site we used the Invertible Forest Reflectance model "INFORM" (Atzberger, 2000; Schlerf and Atzberger, 2006), which is a hybrid RTM that combines the forest light interaction model (Rosema et al., 1992) and SAIL (Verhoef, 1984) canopy RTMs with the PROSPECT (Jacquemoud and Baret, 1990) leaf RTM. In INFORM, LAI is represented by the leaf area indices of single trees. Hence, the ground truth values for LAIs were computed from LAI and CC.

$\mathrm{LAI}_{s}=\frac{\mathrm{LAI}}{\mathrm{CC}}$

And for every combination of model input parameters, LDMC and SLA were indirectly calculated from $C_{m}$ and $C_{w}$ as:

$\mathrm{LDMC}=\frac{C_{m}}{C_{m}+C_{w}}$

$\mathrm{SLA}=\frac{1}{C_{m}}$

where $\mathrm{LAI}_{\mathrm{s}}$ is single tree leaf area index, CC is canopy closure; $C_{m}$ is leaf dry mass and $C_{w}$ is leaf water content per leaf area. See Ali et al. (2016b) for further details.

A strong correlation $\left(R^{2}=0.94\right)$ was observed between the model input parameters $C_{m}$ and $C_{w}$ (Fig. 3). Therefore, in order to preserve the relationship between these input parameters the INFORM model was run by generating the input parameters $\left(C_{m}\right.$, $C_{w}, \mathrm{~N}, \mathrm{LAI}_{\mathrm{s}}, \mathrm{SD}, \mathrm{SH}, \mathrm{CD}$ and ALA) using a multivariate normal distribution function based on the mean and covariance matrix of their ground truth values (Table 1). Leaf chlorophyll content was fixed at an average value of $40 \mu \mathrm{g} / \mathrm{g}$, since in this study the shortwaveinfrared region (SWIR) of the electromagnetic spectrum was used; a region of the electromagnetic spectrum where leaf pigments have no effect. A sensitivity study had previously reported insignificant effect of solar zenith and azimuth angles on INFORM simulated canopy reflectance (Ali et al., 2016a). Therefore, other leaf, canopy, and external input parameters (Table 2) were fixed using average values based on the field data, HySpex sensor specification, and previous studies (Schlerf and Atzberger, 2006; Ali et al., 2016b). As bare soil occurred extremely rarely on the forest floor, the field spectra of understory vegetation and the forest floor elements were averaged and used as a fixed background reflectance during the simulation (Fig. 4).

Next, using the INFORM model 10,000 reflectance spectra were simulated by randomly selecting leaf chemical and canopy structural properties based on the multivariate normal distributions and covariance matrix produced from the ground truth data. To avoid extreme values and unrealistic combinations, the randomly assigned value of each variable was limited by $\pm 5 \%$ of the observed maximum and minimum values for that variable in the ground

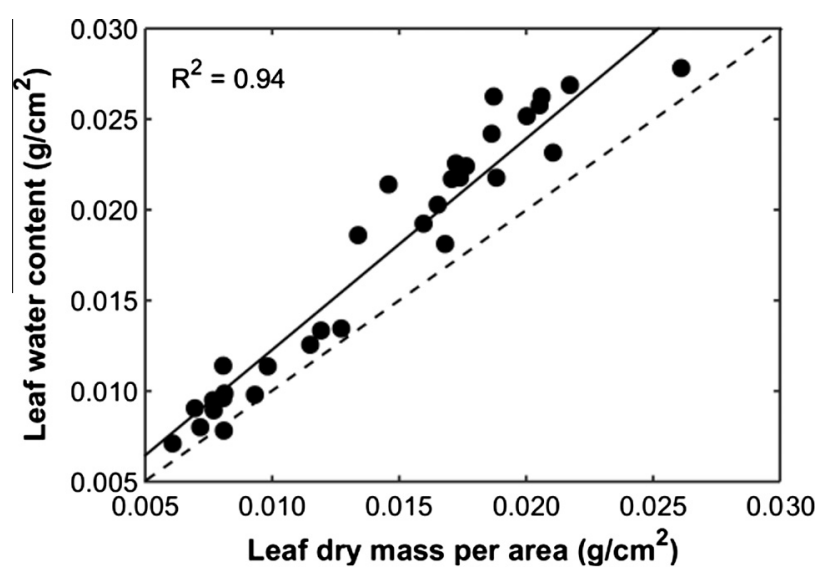

Fig. 3. Correlation between the measured average leaf mass per area $\left(C_{m}\right)$ and average leaf water content $\left(C_{w}\right)$ of the 33 plots. The solid line shows the best linear correlation and the broken line indicates the 1:1 relationship.

truth data. A random Gaussian noise value of $0.3 \%$ (Cheng et al., 2014b) was added to each simulated spectrum to account for model uncertainties and reduce auto-correlation between the spectrum and input variables. The simulation was performed for 256 spectral bands $(1000-2500 \mathrm{~nm})$ corresponding to the SWIR band settings of the HySpex system.

\subsection{Continuous wavelet analysis}

Signal processing, image processing, and data compression have been successfully undertaken in many fields using wavelet transformation (e.g. Tjuatja et al., 1993; FatemiGhomi et al., 1995; Roux et al., 2000; Lin et al., 2008; Jingcheng et al., 2011). The wavelet transform converts each one-dimensional reflectance spectrum into a two-dimensional wavelet power scalogram by using a mother wavelet function. Each element of a wavelet power scalogram is called a wavelet coefficient. The coefficients of CWA can be directly compared with the original spectra wavebands and possess information about the position and shape of the vegetation's spectral features. The continuous wavelet analysis involves the linear transformation of a hyperspectral signal into a set of coefficients using the mother wavelet function $f(\lambda)$ (where $\lambda=1,2,3, \ldots, k$, represent the number of wavebands). The continuous wavelet $\psi a, b(\lambda)$ can be created by scaling and shifting the mother wavelet $\psi(\lambda)$ (Cheng et al., 2011, 2010);

$\psi_{a, b}(\lambda)=\frac{1}{\sqrt{a}}\left(\frac{\lambda-b}{a}\right)$

where $a$ and $b$ are positive real numbers and represent the scaling and shifting factors, respectively. The scale factor $a$ represents the width of the wavelet and the shifting factor $b$ denotes its position.

$W_{f}(a, b)=\left\langle f, \psi_{a, b}\right\rangle=\int_{-\infty}^{+\infty} f(\lambda), \psi_{a, b}(\lambda) d \lambda$ 
Table 2

Constant input parameters used during INFORM simulation based on field observation, HySpex hyperspectral sensor configuration, and previous studies.

\begin{tabular}{|c|c|c|c|c|}
\hline Input variable & Symbol & Unit & Value & Source \\
\hline Chlorophyll content & $C_{a b}$ & $\mu \mathrm{g} / \mathrm{cm}^{2}$ & 40 & Ali et al. (2016) \\
\hline Sun zenith angle & $\theta_{s}$ & Degree & 32 & HySpex data \\
\hline Observation zenith angle & $\theta_{0}$ & Degree & 0 & HySpex data \\
\hline Azimuth angle & $\Psi$ & Degree & 153 & HySpex data \\
\hline Fraction of diffused radiation & Sky1 & Fraction & 0.1 & Schlerf and Atzberger, 2006 \\
\hline
\end{tabular}

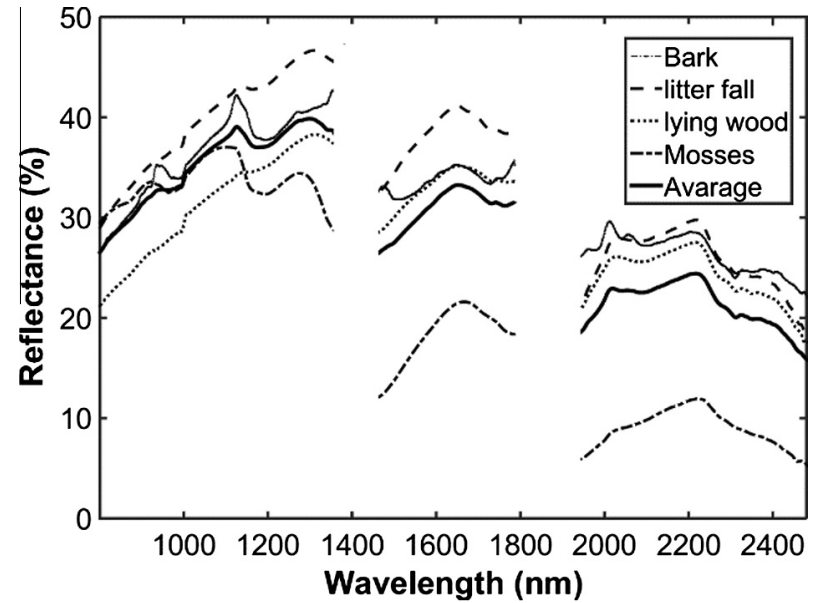

Fig. 4. Spectral property of the Bavarian national park forest floor as measured by ASD spectroradiometer and used as representative background reflectance during INFORM simulation.

The continuous wavelet coefficients $\left(W_{f}(a, b)\right)$ consist of the two-dimensional scalogram $(j \times k$ matrix $)$. The one-dimension depth of leaf spectra resulting from different amounts of LDMC and SLA can be quantified by using the wavelet coefficient (scalogram). Among mother wavelets, available in MATLAB 8.4 software, the second derivative of the Gaussian function (Mexican hat) was selected for both LDMC and SLA since it best correlated the two leaf traits with wavelet features. The Gaussian function has also been proposed as a potential mother wavelet in other remote sensing studies, because it approximates the shape of the absorption features of reflectance spectra (Cheng et al., 2011, 2014a, 2014b; Ullah et al., 2012a).

In wavelet transform scale, values govern the degree to which the wavelet is compacted or stretched. Low scale values compress the wavelet and correlate better with high frequencies. The low scale CWA coefficients represent fine-scale features in the input signal vector. The reverse is true for high scale values. Instead of using all possible scale decompositions, the dyadic scales were used to decompose the spectra, in order to avoid intensive computation as well as to reduce the dimensions of the scalogram and the volume of data. In this study, scales for CWA were powers of $2\left(2^{1}\right.$, $2^{2}, 2^{3}, \ldots, 2^{10}$ ) and were described as power numbers (scale 1 , scale 2 , scale $3, \ldots$, scale 10 ), similar to the other relevant studies (e.g. Ullah et al., 2012b; Cheng et al., 2014a).

Wavelet features that significantly correlated with LDMC or SLA were determined in four steps as described in Cheng et al. (2011, 2014a). First, a continuous wavelet transform was applied to both the simulated (calibration) dataset and measured (HySpex) spectra (validation) dataset, in order to represent them in the wavelet domain where the wavelet power was a function of the wavelength and the scale. Wavelet features of scales 1,2 , and 3 were excluded from the calibration and validation datasets since they have been reported as mostly capturing noise in airborne hyperspectral data. Second, a correlation scalogram was established between the calibration spectra wavelet power at each wavelength, scale location, and LDMC (or SLA) by calculating the coefficient of determination $\left(R^{2}\right)$. The wavelet amplitude was correlated to log-transformed LDMC and SLA values. This resulted in a pool of wavelet features for the calibration dataset that were sensitive to LDMC or to SLA. Wavelet features with large $R^{2}$ values imply high sensitivity to LDMC or to SLA. Third, all features of a correlation scalogram were ranked in descending order of $R^{2}$ and a threshold value of $1 \%$ was applied to delineate and define the feature regions most sensitive to LDMC or to SLA. Fourthly, features with a central wavelength within each region of the combined scalogram were selected, in order to generate a short list of predictor variables: they are described as (wavelength in $\mathrm{nm}$, scale) in the following text. The selected wavelengths and scale values of the wavelet transformed validation dataset (HySpex) were taken out and put aside for validation purpose. The overall analysis process is shown schematically in figure.

\subsection{Calibration of predictive models and inversion}

The Hyspex data inversion was performed using predictive models. Predictive models were developed on the relationships between the simulated spectra wavelet features identified in Section 2.5 and the INFORM model input parameters (LDMC and SLA). A wide variety of regression models such as linear, stepwise linear, multiple linear and quadratic regressions were tested for their performance. Predictive models with good fit (i.e. a high $R^{2}$ and low RMSE combination) on the calibration dataset (INFORM simulated spectra and inputs) were then used to invert the HySpex imagery wavelet features in order to retrieve LDMC and SLA.

\subsection{Validation}

The predictive performance of the inversion was assessed using LDMC and SLA values collected in 33 sample plots in the field. The accuracy of the field measured and predicted values of the two traits from HySpex imagery were evaluated using the coefficient of determination $\left(R^{2}\right)$ and root mean square error in percent (RMSE $\%)$ calculated as:

$R^{2}=1-\frac{\sum\left(y_{i}-y_{i}^{\prime}\right)^{2}}{\sum\left(y_{i}-\bar{y}_{i}\right)^{2}}$

$\operatorname{RMSE}(\%)=\sqrt{\frac{\sum\left(y_{i}-y_{i}^{\prime}\right)^{2}}{n}} / \bar{y}_{i} * 100$

where $y_{i}$ and $y_{i}^{\prime}$ are the actual and predicted values for sample $i$, and $\bar{y}$ and $\mathrm{n}$ are the arithmetic mean and the number of samples in the measured data, respectively.

\subsection{Mapping the LDMC and SLA of the test site}

Once the performance of the different wavelet features was investigated, the selected predictive models were applied to map the concentration of the two leaf traits in the test site. First, the non-forest areas and cloud cover in the HySpex image data were 
masked out using land cover maps, ground sample points and visual inspection. Next, the continuous wavelet transformation was applied and sensitive wavelet features for each pixel in the HySpex image were extracted. Then the predictive models developed in Section 2.6 were applied for pixel-by-pixel estimation of the two leaf traits in the test site. Finally, the predicted values were used to map the spatial distribution of LDMC and SLA in the Bavarian Forest National park.

\section{Results}

\subsection{Canopy reflectance simulation and verification}

The reliability of the INFORM model simulated spectra was verified by comparing their mean and range with those obtained from HySpex hyperspectral image data. As can be observed from Fig. 5, the simulated reflectance spectra showed a good match with the measured reflectance. The two leaf trait values (LDMC and SLA) had a significant effect on the canopy spectra. The INFORM simulated canopy reflectance reduced as the LDMC increased and vice versa for SLA (Fig. 6) across the SWIR of the electromagnetic spectrum.

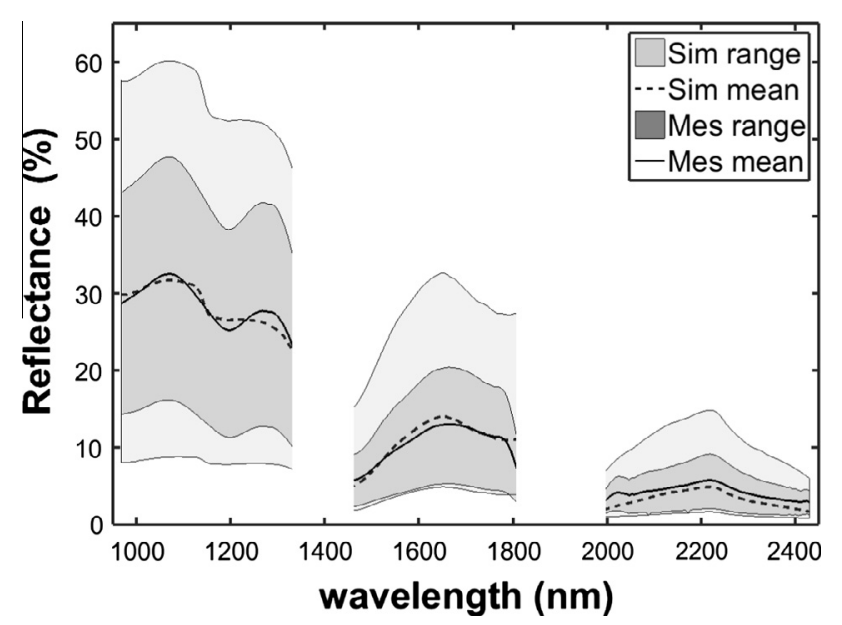

Fig. 5. Comparison of the simulated (sim) spectra (using the INFORM model) with the sample plots' spectra (mes) extracted from HySpex hyperspectral airborne image of the study area. The solid line shows the mean of the sample plots' spectra, while the broken line indicates the mean of simulated spectra. The pale gray and dark gray shaded areas indicate the range of the simulated and measured spectra, respectively.
3.2. Wavelet analysis and identification of wavelet features sensitive to LDMC and SLA

Fig. 7 details the sensitivity of wavelet features (which are transformed from the simulated spectra) plotted for the two leaf traits. Strongly correlated wavelet features were found for both traits. More wavelet features correlate highly with SLA (Fig. 7b) than with LDMC (Fig. 7a). After a number of tests, the top $1 \%$ most strongly correlated wavelet features were found to be good predictors of both traits. There were six sensitive wavelet features for LDMC and four for SLA in the top 1\% strongly correlated wavelet features. The wavelet features selected for LDMC were at scales 4 and 5 , whereas those selected for SLA were at scales 4,6 , and 8 (Fig. $7 \mathrm{~b}$ and d).

\subsection{Fitting regression models to the calibration dataset}

A wide variety of regression models ranging from simple linear to multiple regressions were tested and evaluated to correlate the spectral (wavelet) features with the studied leaf traits. The stepwise linear model and quadratic regression were selected for their goodness of fit to our calibration dataset. The regression models were tested for each wavelet feature separately and for different combinations of wavelet features. Fig. 8 depicts the predictive capacity of two of the many wavelet features selected and their corresponding wavelength reflectance for the two traits estimation.

Fig. $8 \mathrm{c}$ and d demonstrates the overlaid measured spectra fall within the range of the simulated spectra. However, the relationship between the measured spectra wavelet powers and the two traits appears to be shifted toward lower values (Fig. 8a and b). Directly correlating the two plant leaf traits with simulated spectra without any wavelet transformation performed less satisfactorily than correlating them with wavelet power. The reflectance simulated at $2191 \mathrm{~nm}$ turned out to be particularly insensitive to LDMC $\left(R^{2}=0.0003\right)$ (Fig. 8c) whereas the wavelet feature centered at the same band yielded an $R^{2}=0.64$ of linear correlation with LDMC (Fig. 8a). The estimated coefficients of the most accurate stepwise linear prediction equation developed by combining the selected six wavelet features for LDMC retrieval is illustrated in Appendix 1.

Thus, predictions made using selected wavelet features and their combination revealed high $R^{2}$ and low RMSE against the calibration data set of the two leaf traits (Table 3 ). The $\mathrm{R}^{2}$ values range from 0.58 to 0.87 for LDMC and from 0.73 to 0.79 for SLA. The single wavelet features that showed the highest correlation and the lowest RMSE were at $1741 \mathrm{~nm}$ at scale 5 for LDMC and at $1645 \mathrm{~nm}$ at scale 6 for SLA.
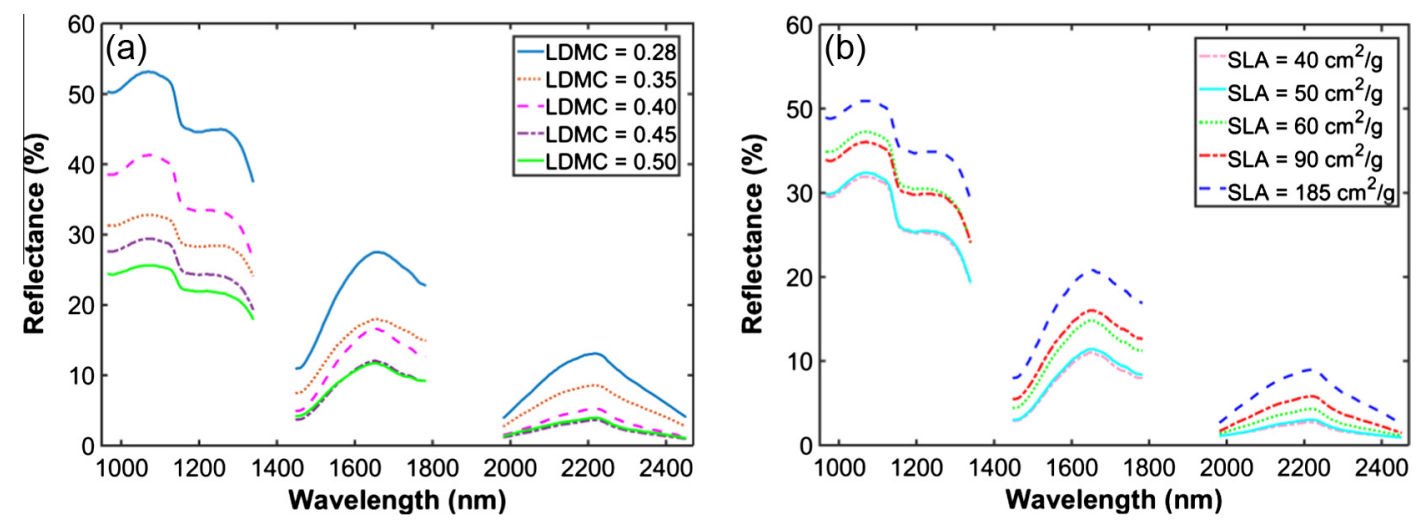

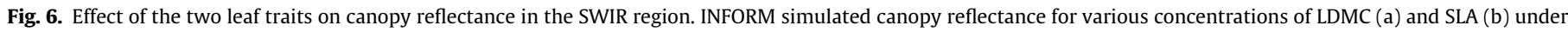
specific canopy structures and sensor configurations. 

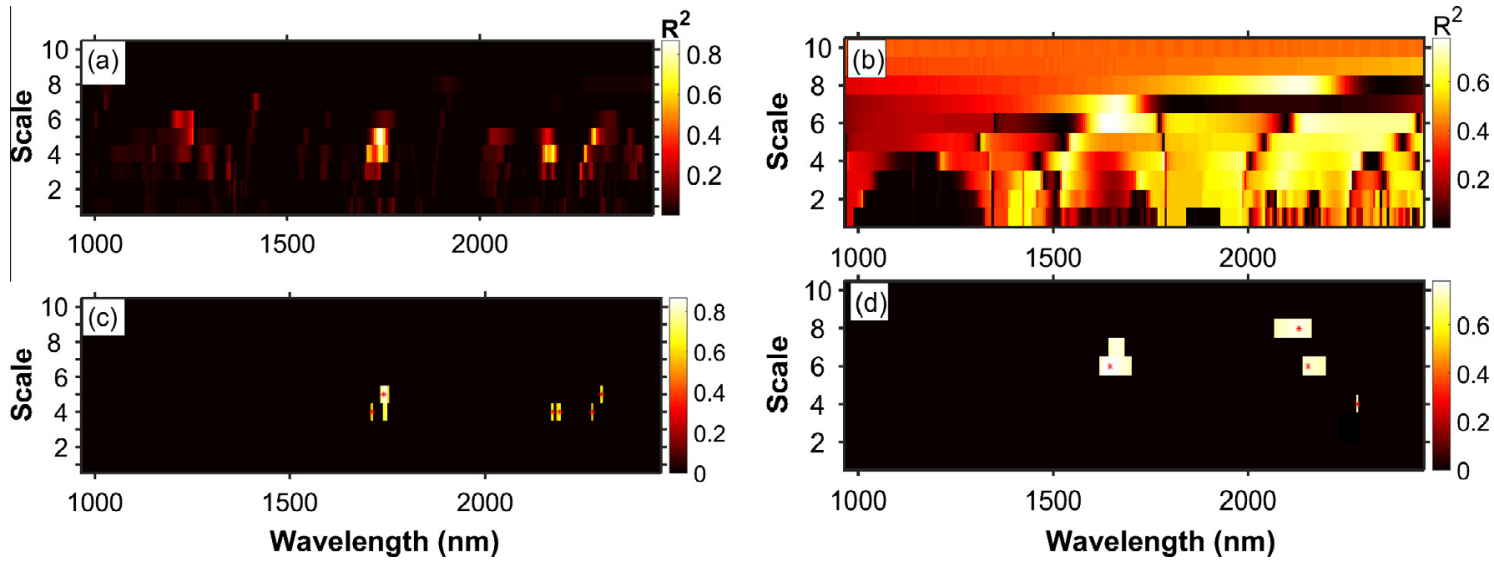

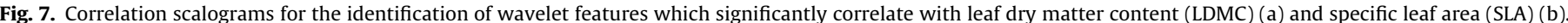

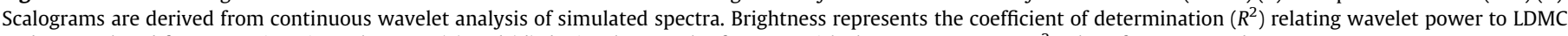
and SLA. Colored feature regions in scalograms (c) and (d) depict the wavelet features with the top $1 \%$ greatest $R^{2}$ values for LDMC and SLA.
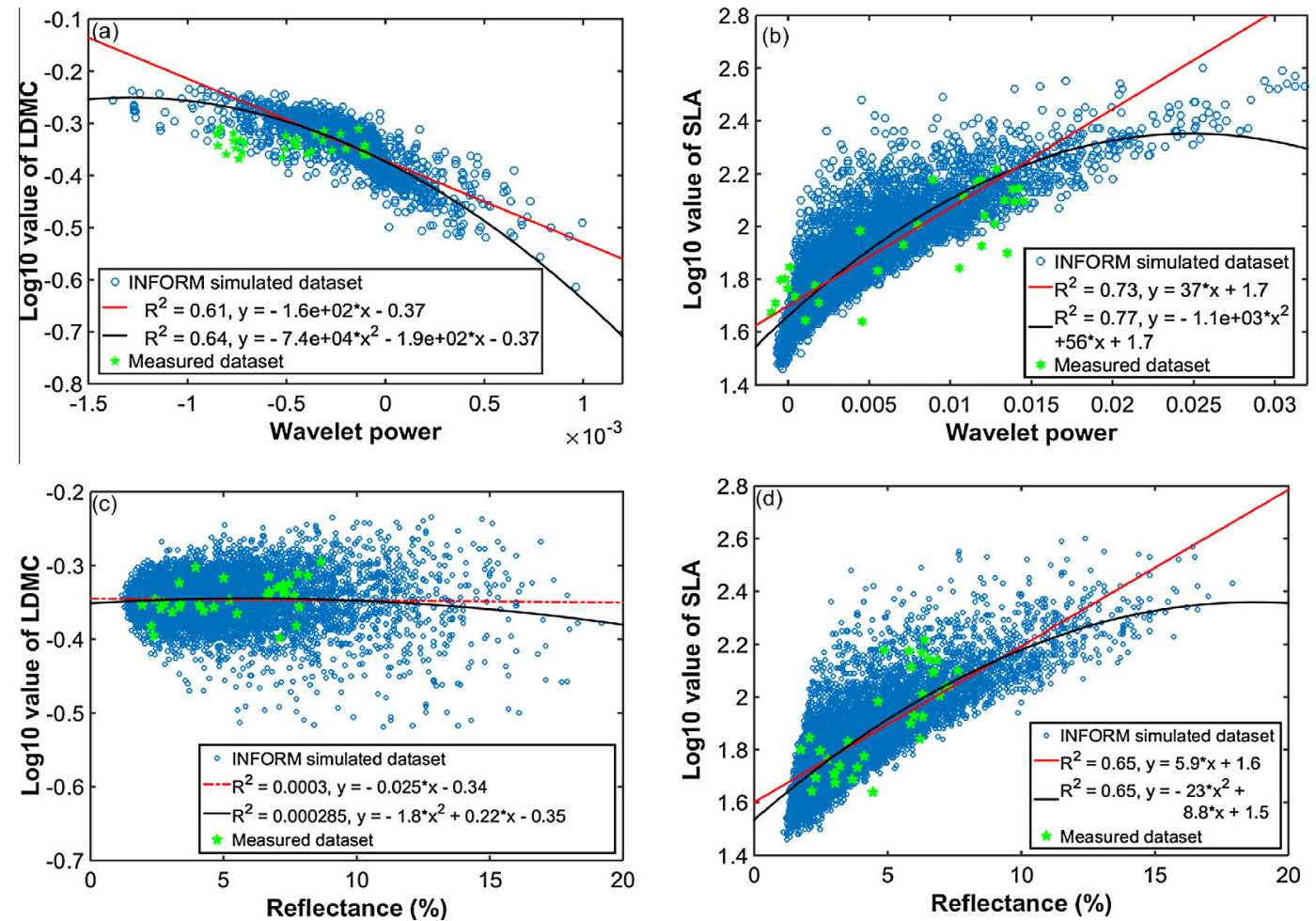

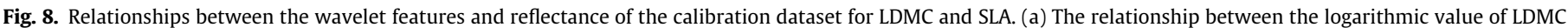

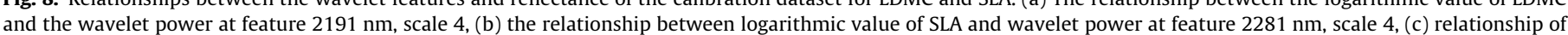

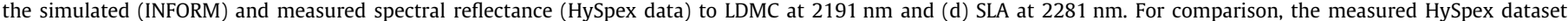
(validation dataset) are shown as pentagrams.

Table 3

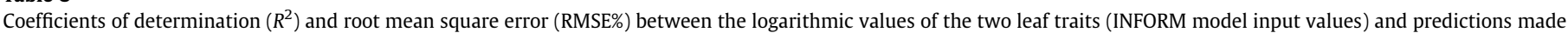
using wavelet features derived from the calibration dataset.

\begin{tabular}{|c|c|c|c|c|c|}
\hline \multicolumn{3}{|l|}{ LDMC } & \multicolumn{3}{|l|}{ SLA } \\
\hline Spectral (wavelet) feature & $R^{2}$ & $\overline{\text { RMSE (\%) }}$ & Spectral (wavelet) feature & $R^{2}$ & RMSE (\%) \\
\hline A. Combination of All & 0.92 & 2.41 & A. Combination of all & 0.93 & 2.50 \\
\hline B. (1741 nm scale 5) & 0.87 & 3.09 & B. Combination of D, F \& G & 0.87 & 3.42 \\
\hline C. (2191 nm scale 4$)$ & 0.78 & 4.07 & C. (Combination of F \& G) & 0.84 & 3.81 \\
\hline D. (2173 nm scale 4) & 0.72 & 4.62 & D. (1645 nm scale 6$)$ & 0.79 & 4.33 \\
\hline E. (2299 nm scale 5) & 0.66 & 5.08 & E. (2131 nm scale 8$)$ & 0.76 & 4.65 \\
\hline F. (1711 nm scale 4$)$ & 0.63 & 5.32 & F. (2155 nm scale 6) & 0.74 & 4.81 \\
\hline G. $2275 \mathrm{~nm}$ scale 4 & 0.58 & 5.63 & G. (2281 nm scale 4$)$ & 0.73 & 4.91 \\
\hline
\end{tabular}




\subsection{Retrieval and validation of LDMC and SLA from wavelet features}

The predictive models (inversion algorithms) presented in Section 3.3 were applied to the actual image dataset (HySpex airborne hyperspectral data) to estimate the two leaf traits. The predictive models were validated for each wavelet feature separately and for different combination of wavelet features. The combination of all six wavelet features gave better results than single or different combinations of wavelet features for LDMC. However, the wavelet feature centered at $2281 \mathrm{~nm}$ scale 4 was most accurate for predicting SLA using the stepwise linear regression model (Table 4) in the validation process.

The comparison of predicted values obtained from the best combinations of wavelet features against the HySpex data after converting logarithmic values to normal values are presented in Fig. 9. As can be observed from the figure, the prediction is more precise for $\operatorname{LDMC}(\mathrm{RMSE}=4.39 \%)$ than for SLA $(\mathrm{RMSE}=4.90 \%)$, while the inverse is true for correlation $\left(R^{2}=0.59\right.$ and $R^{2}=0.85$ for LDMC and SLA respectively) when a logarithmic value is used. There is a tendency for LDMC to be overestimated, especially for higher values of LDMC. Nevertheless, the predicted values were scattered closely around the 1:1 relationship line, which indicates the sensitivity of the selected wavelet features in capturing the variation in LDMC and SLA concentrations. Furthermore, no saturation problems were observed in the predicted values.

\subsection{Mapping the LDMC and SLA of the study area}

The concentrations of the two leaf traits across the study area (Bavarian Forest National Park) are presented in Fig. 10a and b. Before producing the maps, a forest mask obtained from maximum likelihood classification (MLC) was used to mask out the non-forest areas from the HySpex data, thus eliminating areas occupied by other land covers. The accuracy of the created forest mask by MLC was assessed using the existing land cover maps and the 33 sample plots data (kappa coefficient $=0.95$ ) (see Appendix 2 for details). The masked HySpex image and the selected predictive models developed from six wavelet features for LDMC and one wavelet feature for SLA (Table 4) were applied to map these traits. The inverse relationship of the two leaf traits is clearly visible in the maps. Both LDMC and SLA showed perceptible variability across the study area. The means obtained for all image pixels were 0.4235 for LDMC $\mathrm{g} / \mathrm{g}$ and $107 \mathrm{~cm}^{2} / \mathrm{g}$ for SLA, which are close to the means of the samples measured during the field measurements shown in Table 1. A comparison with a forest type map of the test site revealed that LDMC values were higher for conifer and mixed stands than for deciduous forests (Fig. 10c).

\section{Discussion and conclusion}

\subsection{Wavelet transformation and inversion}

In the last four decades, vegetation biophysical and biochemical variables have been retrieved from remote sensing data using either statistical (empirical) or physical (RTM) approaches. However, previous studies mainly focused on estimating parameters by seeking the direct correlation between remote sensing data and parameter values. The method used for retrieving variables from physical models involved the generation of a large dataset of simulated spectra followed by inversion using approaches like look-up tables or an artificial neural network. To date, the potential for estimating vegetation variables using transformed spectra has not been investigated. Our study has for the first time successfully retrieved the two leaf traits namely, LDMC and SLA from canopy reflectance data obtained from airborne hyperspectral image by means of RTM and wavelet transformation.

Table 4

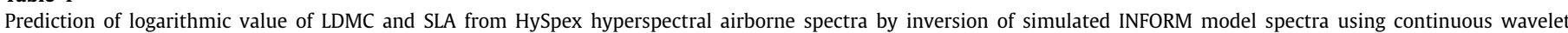
transformation and stepwise linear regression.

\begin{tabular}{|c|c|c|c|c|c|}
\hline \multicolumn{3}{|l|}{ LDMC } & \multicolumn{3}{|l|}{ SLA } \\
\hline Spectral (wavelet) feature & $R^{2}$ & RMSE (\%) & Spectral (wavelet) feature & $R^{2}$ & $\overline{\text { RMSE }(\%)}$ \\
\hline A. Combination of all & 0.59 & 4.39 & A. (2281 nm scale 4 ) & 0.85 & 4.90 \\
\hline B. (1741 nm scale 5) & 0.39 & 23.10 & B. Combination of all & 0.85 & 36.44 \\
\hline C. (2275 nm scale 4) & 0.34 & 24.29 & C. Combination of A, E \& G & 0.84 & 13.03 \\
\hline D. (2191 nm scale 4) & 0.33 & 17.26 & D. Combination of E \& G & 0.80 & 5.43 \\
\hline E. (2299 nm scale 5) & 0.2 & 20.08 & E. (2155 nm scale 6) & 0.50 & 7.86 \\
\hline F. (2173 nm scale 4$)$ & 0.30 & 21.27 & F. (2131 nm scale 8 ) & 0.48 & 7.36 \\
\hline G. (1711 scale 4$)$ & 0.28 & 20.82 & G. (1645 nm scale 6$)$ & 0.32 & 12.94 \\
\hline
\end{tabular}
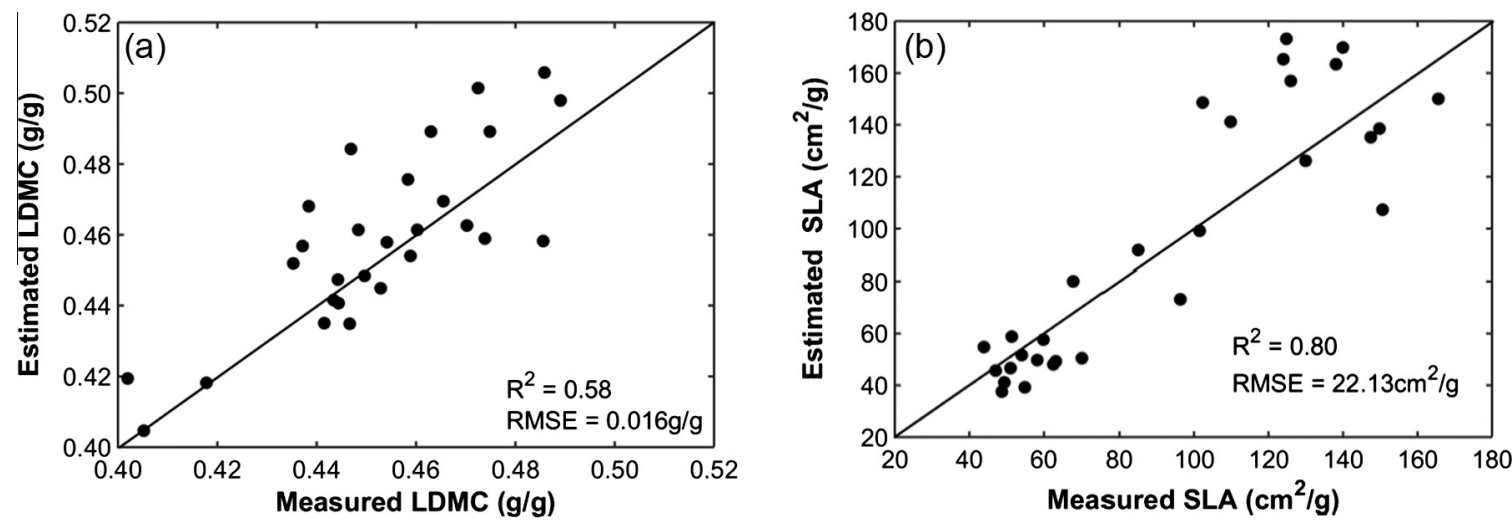

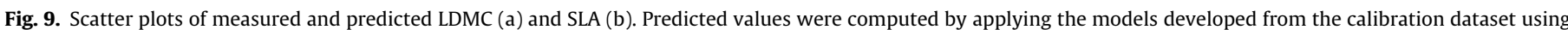

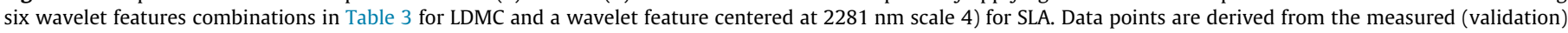
dataset collected from the study site. The solid line shows the 1:1 relationship between the predicted and measured data. 

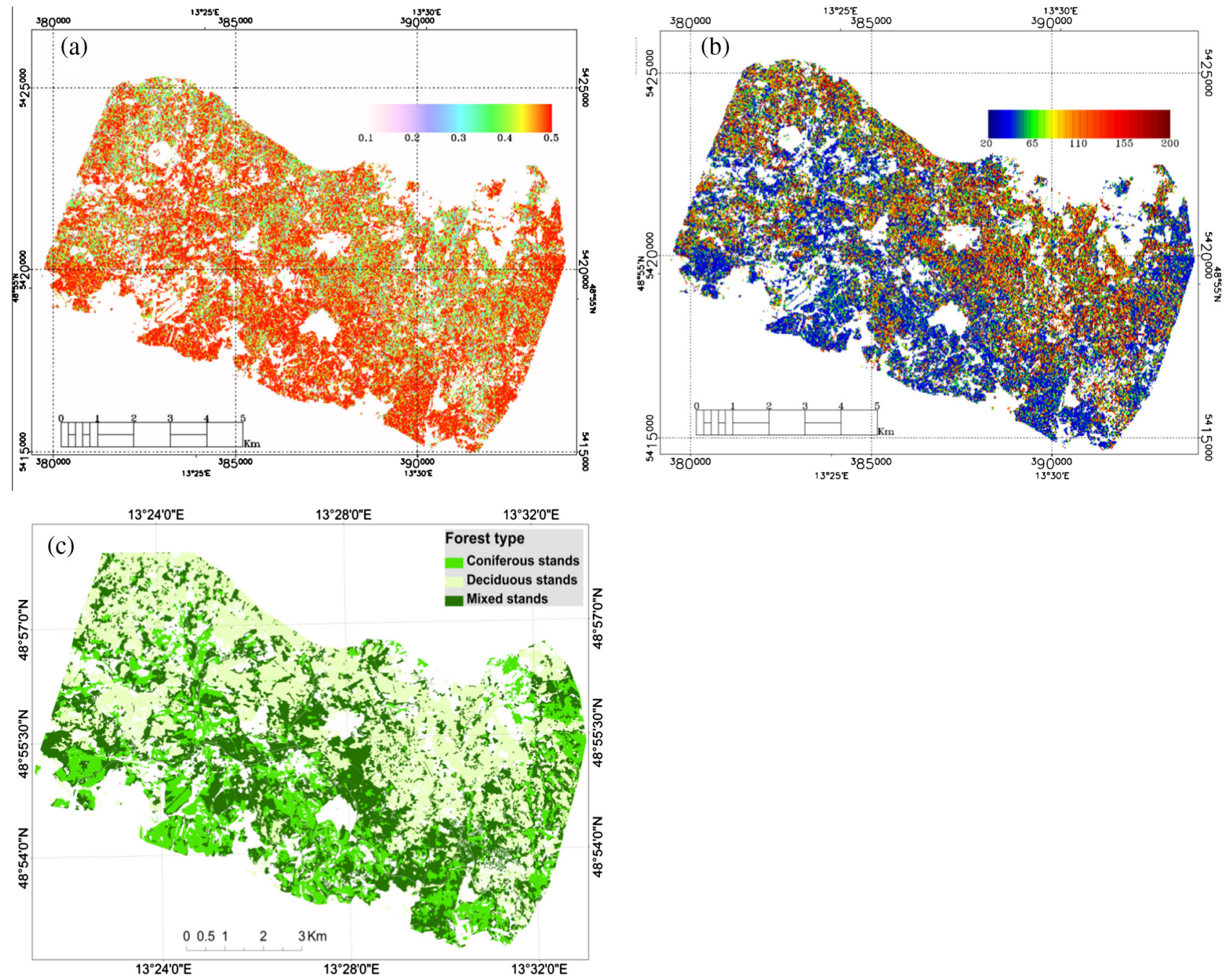

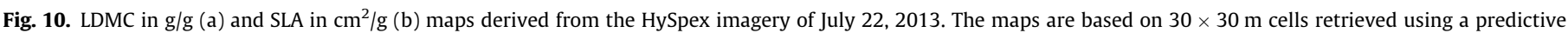

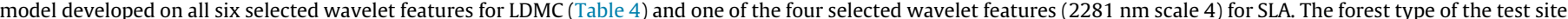
is shown (c) for comparison of the spatial distribution of the two leaf traits across different forest stands.

\subsection{Advantage of wavelet transformation}

In this study, the CWA approach was used for the retrieval of the two functional traits from HySpex hyperspectral reflectance data. One advantage of CWA over other approaches is that it has the potential to identify the most sensitive spectral features from a large hyperspectral dataset. The second advantage of using CWA is transformation of the original spectra that resulted in stronger correlation between the variables. Decomposition of the INFORM simulated spectra and measured HySpex spectral reflectance using CWA $\left(R^{2}=0.58-0.93\right)$ provided higher correlations with the two leaf traits compared with the non-transformed reflectance values $\left(R^{2}=0.0003-0.65\right)$.

Our results demonstrate the validity of CWA for estimating vegetation variables in particular leaf traits such as LDMC and SLA (Fig. 8). After wavelet transformation, parameters which appeared uncorrelated to simulated canopy reflectance (without transformation), such as LDMC, were observed to be highly correlated (Fig. 8a and c). This may be attributed to the effectiveness of CWA in decomposing the traits' absorption features into various scales of narrow and broad band absorption features and identifying those that correlate most with the variation in the traits' concentration. The performance of wavelet analysis compared with narrow-band indices and stepwise selection of narrow-band reflectance for retrieval of pigment concentrations in vegetation at leaf and canopy scales has also been reported by Blackburn (2007b). By comparison with narrow-band indices, wavelet analysis captures more information contained within the hyperspectral data and creates an opportunity to develop robust and extendible methods for quantifying plant traits over extended areas (Blackburn, 2007a).

\subsection{Identifying strongly correlated wavelet features}

We determined six wavelet features for LDMC and four for SLA prediction in a mixed mountain forest (Table 4). The prediction model based on all six selected wavelet features performed with higher accuracy than any other combination of wavelet features for LDMC retrieval. However, for SLA, one unanticipated finding was that the wavelet feature at $2281 \mathrm{~nm}$ scale 4 provided a more accurate prediction of SLA than any other individual features and their combinations. This demonstrates the fact that application of all strongly correlated wavelet features to calibration data sets may lead to overfitting and does not necessarily ensure the most accurate estimation. 
Appendix 1

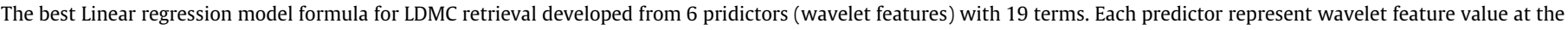
given wavelength and scale: $a=(1711 \mathrm{~nm}$ scale 4$), b=(1741 \mathrm{~nm}$ scale 5$), c=(2173 \mathrm{~nm}$ scale 4$), d=(2191 \mathrm{~nm}$ scale 4$), e=(2275 \mathrm{~nm}$ scale 4$)$ and $f=(2299 \mathrm{~nm}$ scale 5$)$.

\begin{tabular}{|c|c|c|c|c|}
\hline & \multicolumn{4}{|c|}{ Estimated coefficients } \\
\hline & Estimate & SE & tStat & pValue \\
\hline Intercept & -0.37 & 0.001 & -280.06 & 0 \\
\hline (1711 nm scale 4) & 2.78 & 1.243 & 2.239 & 0.0252 \\
\hline (1741 nm scale 5) & -25.96 & 0.548 & -47.375 & 0 \\
\hline (2173 nm scale 4) & 19.19 & 6.016 & 3.190 & 0.001 \\
\hline (2191 nm scale 4) & 68.51 & 5.672 & 12.079 & 0 \\
\hline (2275 nm scale 4) & -12.45 & 2.870 & -4.337 & 0 \\
\hline (2299 nm scale 5) & -12.68 & 0.938 & 13.516 & 0 \\
\hline (1711 nm scale 4$) *(1741 \mathrm{~nm}$ scale 5$)$ & 4523.7 & 286.98 & 15.763 & 0 \\
\hline$(1711 \mathrm{~nm}$ scale 4$) *(2173 \mathrm{~nm}$ scale 4$)$ & -13529 & 3078.8 & 4.394 & 0 \\
\hline$(1711 \mathrm{~nm}$ scale 4$) *(2191 \mathrm{~nm}$ scale 4$)$ & -24490 & 3605.1 & 6.793 & 0 \\
\hline (1711 nm scale 4$) *(2299 \mathrm{~nm}$ scale 5$)$ & 2761.4 & 476.57 & 5.794 & 0 \\
\hline$(1741 \mathrm{~nm}$ scale 5$) *(2173 \mathrm{~nm}$ scale 4$)$ & 5873.5 & 1114.4 & 5.271 & 0 \\
\hline$(1741 \mathrm{~nm}$ scale 5$) *(2191 \mathrm{~nm}$ scale 4$)$ & 6822.1 & 954.03 & 7.151 & 0 \\
\hline$(1741 \mathrm{~nm}$ scale 5$) *(2275 \mathrm{~nm}$ scale 4$)$ & -8598.3 & 1026.2 & -8.379 & 0 \\
\hline$(1741 \mathrm{~nm}$ scale 5$) *(2299 \mathrm{~nm}$ scale 5$)$ & -1838.9 & 264.17 & -6.961 & 0 \\
\hline$(2173 \mathrm{~nm}$ scale 4$) *(2275 \mathrm{~nm}$ scale 4$)$ & 32559 & 7925 & 4.108 & 0 \\
\hline$(2173 \mathrm{~nm}$ scale 4$) *(2299 \mathrm{~nm}$ scale 5$)$ & -11629 & 3037.2 & -3.829 & 0 \\
\hline (2191 nm scale 4$) *(2275 \mathrm{~nm}$ scale 4$)$ & 37772 & 6081.3 & 6.211 & 0 \\
\hline (2191 nm scale 4$) *(2299 \mathrm{~nm}$ scale 5$)$ & -6341.8 & 1042.3 & -6.084 & 0 \\
\hline
\end{tabular}

Appendix 2

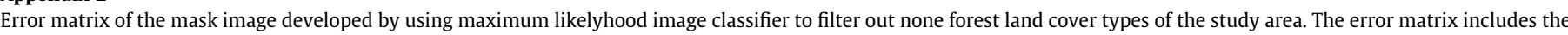
overall accuracy, kappa coefficient, confusion matrix, errors of commission, errors of omission, producer accuracy, and user accuracy.

\begin{tabular}{|c|c|c|c|c|}
\hline & \multicolumn{4}{|l|}{ Confusion matrix } \\
\hline & Ground truth (pixels) & & & \\
\hline \multirow{5}{*}{ Classification } & Class & Forest & Non-forest & Total \\
\hline & Forest & 138 & 8 & 146 \\
\hline & Non-forest & 5 & 99 & 104 \\
\hline & Total & 143 & 107 & 250 \\
\hline & Ground truth (percent) & & & \\
\hline \multirow[t]{4}{*}{ Classification } & Class & Forest & Non-forest & Total \\
\hline & Forest & 96.5 & 7.5 & 58.4 \\
\hline & Non-forest & 3.5 & 92.5 & 41.6 \\
\hline & Total & 100 & 100 & 100 \\
\hline Class & Error of commission (percent) & Error of omision (percent) & Preducer accuracy (percent) & User accuracy (percent) \\
\hline Forest & 5.479 & 3.496 & 94.5 & 96.5 \\
\hline Non-forest & 4.807 & 7.477 & 95.2 & 92.5 \\
\hline
\end{tabular}

Averall accuracy $=(138+99) / 250=94.8 \%$.

Kappa coefficient $=0.9478$.

The band position of the SLA-sensitive wavelet features found in this study agrees well with findings by Cheng et al. (2014b), who used simulated and measured spectra at leaf level and reported a strong correlation of LMA (inverse of SLA) with the wavelet features at (1639 nm, scale 4) and (2139 nm, scale 4). However, in our study the scale of the wavelet features has shifted to larger values. This may be due to canopy structure properties and other external factors such as sensor configuration and atmospheric effects that would influence the canopy spectral reflectance.

In our study, for both LDMC and SLA many of the sensitive bands occurred in the longer wavelengths of the SWIR region of the electromagnetic spectrum (Tables 3 and 4): 1500-2500 nm. This reconfirms that SWIR wavelengths are the most sensitive to leaf dry matter variations, which is in accordance with the results from Jacquemoud et al. (1996), le Maire et al. (2008) and Feret et al. (2011). By comparison with other spectral regions, the SWIR region efficiently avoids the influence of other parameters such as leaf pigments. The wavelengths found in this study were in agreement with the findings of Thenkabail et al. (2004), who recommended 22 bands for multi-spectral remote sensing of vegetation. The proposed bands in this study were among bands which are very sensitive to changes (or differences) in biochemical properties such as lignin, starch, and cellulose as well as plant stress (Prasad et al., 2011).

\subsection{Accuracy assessment}

As expected, the measured HySpex spectra overlapped exactly with the simulated spectra without transformation (Figs. 5 and 8c, d). However, despite the addition of $0.3 \%$ random Gaussian noise to the simulated spectra, systematic shifts to higher or lower values were observed when wavelet transformation was applied to the measured spectra (Fig. 8a and b). This in turn led to systematic overestimation and underestimation of the two traits (Fig. 9). Probable causes for this shift could be atmospheric effects and sensor noise on the measured spectra. These factors may cause variation in local absorption peaks (magnitude of reflectance) on the measured spectra, and lead to higher or lower wavelet power values during the transformation.

Another possible reason could be the simplification of parameters in RTM representation. The model input parameters are based on certain input parameters and the effect of the forest heterogeneity cannot be fully estimated the stochastic processes. Therefore, strong correlations may be found between any of the input parameters and the simulated spectra or their derivatives. This is consistent with the results obtained by Cheng et al. (2014b), who also found wavelet power better fitted the leaf spectra simulated with the PROSPECT model than the spectra measured from leaf samples in the laboratory. They partly attributed the differences 
to measurement errors and simplifications intrinsic to PROSPECT. Similarly, Feret et al. (2011) and le Maire et al. (2008) reported stronger correlation between one of the model input variables and simulated spectra than between measured variables and spectra.

We found a stronger correlation between the predicted and (measured) validation values for SLA $\left(R^{2}=0.80\right)$ than for LDMC $\left(R^{2}=0.58\right)$. Similar outcomes have also been reported previously (Ali et al., 2016b) for estimating the two leaf traits from the PROSPECT model inversion at leaf scale. These may be attributed to several factors. One possible reason is that LDMC is a compound variable derived from leaf water content $\left(C_{w}\right)$ and leaf dry mass per unit area $\left(C_{m}\right)$. Therefore, its correlation with spectral reflectance is affected by both $C_{w}$ and $C_{m}$. This may explain why many of the wavelengths did not show strong correlation to LDMC even in the simulated spectra (Fig. 7). The relatively low $R^{2}$ value (as low as 0.58 ) between simulated spectral wavelet features and LDMC while that of SLA was above 0.70 (Table 3 ) also supports the contention that LDMC is less correlated with reflectance than SLA (Ali et al., 2016b).

By contrast, the RMSE for LDMC was found to be lower than the RMSE for SLA (4.39\% versus 4.90\%: Fig.7). The low RMSE of LDMC may be partially associated with ground truth accuracy. LDMC is computed based on fresh and dry weights of samples that can be precisely and accurately obtained in the laboratory, but calculation of SLA requires measurements of leaf area that are prone to operator and instrument errors.

We did not observe significant improvements in the predictions made for deciduous, coniferous, and mixed stands separately (results not shown here). This reveals the unbiased nature of the average value weighted by the crown proportion of each species present in a mixed sample plot. However, calculating the crown volume involves extra field efforts to collect parameters such as crown diameter, crown height, total height, diameter at breast height, and other forest inventory data.

In broad terms, our findings have revealed the potential for estimating forest leaf traits from imaging spectroscopy using radiative transfer model and CWA. Here we examined the predictability of the two leaf traits in the $950-2450 \mathrm{~nm}$ spectral region only. The other parts of the electromagnetic spectrum should be investigated and the methods should be refined in order to address the quantification of plant traits across a wide range of spatial scales. other traits could similarly be explored.

\section{Acknowledgments}

This study was funded by Netherlands fellowship program. We acknowledge the assistance of Dr. Nicole Pinnel in the German Remote Sensing Data Center (DLR) and Dr. Hooman Latifi in the Institute of Geography and Geology, University of Würzburg in selecting the test site, and facilitating the field campaign. Thanks also go to the Bavarian Forest National Park particularly to $\mathrm{Dr}$ Marco Heurich and Wilhelm Breit for approving access to the study area, providing the crossbow with its accessories, and other field and logistical facilities. The authors also wish to thank Zhihui Wang and Tiejun Wang in the faculty of Geo-Information Science and Earth Observation, University of Twente, who assisted with the fieldwork design and data collection. We are grateful to Dr. Joy Burrough for the language editing of a near-final draft of this paper.

\section{Appendix A}

See Appendices 1 and 2.

\section{References}

Ali, A.M., Darvishzadeh, R., Skidmore, A.K., Duren, I.V., 2016a. Effects of canopy structural variables on retrieval of leaf dry matter content and specific leaf area from remotely sensed data. IEEE J. Select. Topics Appl. Earth Observ. Remote Sens, 9 (2), 898-909.

Ali, A.M., Darvishzadeh, R., Skidmore, A.K., Duren, I.v., Heiden, U., Heurich, M., 2016b. Estimating leaf functional traits by inversion of PROSPECT: assessing leaf dry matter content and specific leaf area in mixed mountainous forest. Int. J. Appl. Earth Obs. Geoinf. 45 (Part A), 66-76.

Atzberger, C., 2000. Development of an invertible forest reflectance model: The INFOR-Model. In: Buchroithner (Ed.). A decade of trans-European remote sensing cooperation: Proceedings of the 20th EARSeL Symposium Dresden, Germany, 14-16. June 2000, pp. 2039-2044.

Atzberger, C., Darvishzadeh, R., Immitzer, M., Schlerf, M., Skidmore, A., le Maire, G., 2015. Comparative analysis of different retrieval methods for mapping grassland leaf area index using airborne imaging spectroscopy. Int. J. Appl. Earth Obs. Geoinf. 43, 19-31.

Banskota, A., Wynne, R.H., Serbin, S.P., Kayastha, N., Thomas, V.A., Townsend, P.A., 2013a. Utility of the wavelet transform for LAI estimation using hyperspectral data. Photogram. Eng. Remote Sens. 79 (7), 653-662.

Banskota, A., Wynne, R.H., Thomas, V.A., Serbin, S.P., Kayastha, N., GastelluEtchegorry, J.P., Townsend, P.A., 2013b. Investigating the utility of wavelet transforms for inverting a 3-D radiative transfer model using hyperspectral data to retrieve forest LAI. Remote Sens. 5 (6), 2639-2659.

Blackburn, G.A., 2007a. Hyperspectral remote sensing of plant pigments. J. Exp. Bot. $58(4), 855-867$.

Blackburn, G.A., 2007b. Wavelet decomposition of hyperspectral data: a novel approach to quantifying pigment concentrations in vegetation. Int. J. Remote Sens. 28 (12), 2831-2855.

Cheng, T., Riano, D., Ustin, S.L., 2014a. Detecting diurnal and seasonal variation in canopy water content of nut tree orchards from airborne imaging spectroscopy data using continuous wavelet analysis. Remote Sens. Environ. 143, 39-53.

Cheng, T., Rivard, B., Sánchez-Azofeifa, A., 2011. Spectroscopic determination of leaf water content using continuous wavelet analysis. Remote Sens. Environ. 115 (2), 659-670.

Cheng, T., Rivard, B., Sánchez-Azofeifa, A.G., Féret, J.-B., Jacquemoud, S., Ustin, S.L., 2014b. Deriving leaf mass per area (LMA) from foliar reflectance across a variety of plant species using continuous wavelet analysis. ISPRS J. Photogram. Remote Sens. 87, 28-38.

Cheng, T., Rivard, B., Sánchez-Azofeifa, A.G., Féret, J.B., Jacquemoud, S., Ustin, S.L., 2012. Predicting leaf gravimetric water content from foliar reflectance across a range of plant species using continuous wavelet analysis. J. Plant Physiol. 169 (12), 1134-1142.

Cheng, T., Rivard, B., Sánchez-Azofeifa, G.A., 2010. Spectroscopic determination of leaf water content using continuous wavelet analysis.

Cho, M.A., Ramoelo, A., Mathieu, R., 2014. Estimation of Leaf Area Index (LAI) of South Africa from modis imagery by inversion of prosail radiative transfer model, 2014 IEEE International Geoscience and Remote Sensing Symposium (IGARSS), pp. 2590-2593.

Darvishzadeh, R., Atzberger, C., Skidmore, A., Schlerf, M., 2011. Mapping grassland leaf area index with airborne hyperspectral imagery: a comparison study of statistical approaches and inversion of radiative transfer models. ISPRS J. Photogram. Remote Sens. 66 (6), 894-906.

Darvishzadeh, R., Atzberger, C., Skidmore, A.K., Abkar, A.A., 2009. Leaf Area Index derivation from hyperspectral vegetation indices and the red edge position. Int. J. Remote Sens. 30 (23), 6199-6218.

Darvishzadeh, R., Matkan, A.A., Ahangar, A.D., 2012. Inversion of a radiative transfer model for estimation of rice canopy chlorophyll content using a lookup-table approach. IEEE J. Select. Topics Appl. Earth Observ. Remote Sens. 5 (4), 1222-1230.

Darvishzadeh, R., Skidmore, A., Schlerf, M., Atzberger, C., 2008. Inversion of a radiative transfer model for estimating vegetation LAI and chlorophyll in a heterogeneous grassland. Remote Sens. Environ. 112 (5), 2592-2604.

Dini, L., Vuolo, F., Randazzo, L., 2006. Leaf Area Index retrieval from SPARC data: assessment of radiative transfer model inversion. Earth Observ. Vegetation Monitor. Water Manage. 852, 219-226.

Dorigo, W.A., 2012. Improving the robustness of cotton status characterisation by radiative transfer model inversion of multi-angular CHRIS/PROBA data. IEEE J. Select. Topics Appl. Earth Observ. Rem. Sens. 5 (1), 18-29.

FatemiGhomi, N., Petrou, M., Palmer, P.L., 1995. Wavelet texture analysis for remote sensing. Image Signal Process. Remote Sens. II 2579, 329-340.

Feret, J.B., Francois, C., Gitelson, A., Asner, G.P., Barry, K.M., Panigada, C., Richardson, A.D., Jacquemoud, S., 2011. Optimizing spectral indices and chemometric analysis of leaf chemical properties using radiative transfer modeling. Remote Sens. Environ. 115 (10), 2742-2750.

Heurich, M., Beudert, B., Rall, H., Krenova, Z., 2010. National Parks as model regions for interdisciplinary long-term ecological research. In: Müller, F., Baessler, C., Schubert, H., Klotz, S. (Eds.), Long-term Ecological Research. Between Theory and Application. Springer, Netherlands, pp. 327-344.

Heurich, M., Neufanger, M., 2005. Die Wälder des Nationalparks Bayerischer Wald. Ergebnisse der Waldinventur 2002/2003 im geschichtlichen und waldökologischen Kontext. Grafenau, $178 \mathrm{~S}$.

Hodgson, J.G., Montserrat-Marti, G., Charles, M., Jones, G., Wilson, P., Shipley, B., Sharafi, M., et al., 2011. Is leaf dry matter content a better predictor of soil fertility than specific leaf area? Ann. Bot. 108 (7), 1337-1345. 
Jacquemoud, S., Baret, F., 1990. Prospect - a model of leaf optical-properties spectra. Remote Sens. Environ. 34 (2), 75-91.

Jacquemoud, S., Ustin, S.L., Verdebout, J., Schmuck, G., Andreoli, G., Hosgood, B., 1996. Estimating leaf biochemistry using the PROSPECT leaf optical properties model. Remote Sens. Environ. 56 (3), 194-202.

Jingcheng, Z., Juhua, L., Wenjiang, H., Jihua, W., 2011. Continuous wavelet analysis based spectral feature selection for winter wheat yellow rust detection. Intell. Auto. Soft Comput. 17 (5), 531-540.

Kazemipour, F., Launeau, P., Meleder, V., 2010. A new approach for microphytobenthos biomass mapping by inversion of simple radiative transfer model: application to hyspex images of Bourgneuf Bay. IEEE Int. Geosci. Remote Sens. Sympos., 433-436

Kennedy, R.E., Cohen, W.B., Takao, G., 1997. Empirical methods to compensate for a view-angle-dependent brightness gradient in AVIRIS imagery. Remote Sens. Environ. 62 (3), 277-291.

Lavorel, S., Grigulis, K., Lamarque, P., Colace, M., Garden, D., Girel, J., Pellet, G., Douzet, R., 2011. Using plant functional traits to understand the landscape distribution of multiple ecosystem services. J. Ecol. 99 (1), 135-147.

le Maire, G., Francois, C., Soudani, K., Berveiller, D., Pontailler, J.Y., Breda, N., Genet, H., Davi, H., Dufrene, E., 2008. Calibration and validation of hyperspectral indices for the estimation of broadleaved forest leaf chlorophyll content, leaf mass per area, leaf area index and leaf canopy biomass. Remote Sens. Environ. 112 (10), 3846-3864.

Lehnert, L.W., Bässler, C., Brandl, R., Burton, P.J., Müller, J., 2013. Conservation value of forests attacked by bark beetles: highest number of indicator species is found in early successional stages. J. Nat. Conserv. 21 (2), 97-104.

Lin, Y.B., Lin, Y.P., Deng, D.P., Chen, K.W., 2008. Integrating remote sensing data with directional two-dimensional wavelet analysis and open geospatial techniques for efficient disaster monitoring and management. Sensors 8 (2), 1070-1089.

Lv, J., Yan, Z.G., Wei, J.Y., 2014. Inversion of a radiative transfer model for estimation of rice chlorophyll content using support vector machine, Land Surface Remote Sens. Ii 9260.

Lymburner, L., Beggs, P.J., Jacobson, C.R., 2000. Estimation of canopy-average surface-specific leaf area using Landsat TM data. Photogram. Eng. Remote Sens. 66 (2), 183-191.

Marenco, R.A., Antezana-Vera, S.A., Nascimento, H.C.S., 2009. Relationship between specific leaf area, leaf thickness, leaf water content and SPAD-502 readings in six Amazonian tree species. Photosynthetica 47 (2), 184-190.

Meroni, M., Colombo, R., Panigada, C., 2004. Inversion of a radiative transfer model with hyperspectral observations for LAI mapping in poplar plantations. Remote Sens. Environ. 92 (2), 195-206.

Messier, J., McGill, B.J., Lechowicz, M.J., 2010. How do traits vary across ecological scales? A case for trait-based ecology. Ecol. Lett. 13 (7), 838-848.

Mouchet, M.A., Villéger, S., Mason, N.W.H., Mouillot, D., 2010. Functional diversity measures: an overview of their redundancy and their ability to discriminate community assembly rules. Funct. Ecol. 24 (4), 867-876.

Ollinger, S.V., 2011. Sources of variability in canopy reflectance and the convergent properties of plants. New Phytol. 189 (2), 375-394.

Pierce, L.L., Running, S.W., Walker, J., 1994. Regional-scale relationships of leaf-area index to specific leaf-area and leaf nitrogen-content. Ecol. Appl. 4 (2), 313-321.

Prasad, T., John, L., Alfredo, H., 2011. Hyperspectral Remote Sensing of Vegetation and Agricultural Crops. CRC Press, pp. 663-688.

Rosema, A., Verhoef, W., Noorbergen, H., Borgesius, J.J., 1992. A new forest light interaction-model in support of forest monitoring. Remote Sens. Environ. 42 (1), 23-41.

Roux, S.G., Arneodo, A., Decoster, N., 2000. A wavelet-based method for multifractal image analysis. III. Applications to high-resolution satellite images of cloud structure. Eur. Phys. J. B 15 (4), 765-786.
Schlerf, M., Atzberger, C., 2006. Inversion of a forest reflectance model to estimate structural canopy variables from hyperspectral remote sensing data. Remote Sens. Environ. 100 (3), 281-294.

Shipley, B., 2002. Trade-offs between net assimilation rate and specific leaf area in determining relative growth rate: relationship with daily irradiance. Funct. Ecol. 16 (5), 682-689.

Shipley, B., 2006. Net assimilation rate, specific leaf area and leaf mass ratio: which is most closely correlated with relative growth rate? A meta-analysis. Funct. Ecol. 20 (4), 565-574.

Si, Y., Schlerf, M., Zurita-Milla, R., Skidmore, A., Wang, T., 2012. Mapping spatiotemporal variation of grassland quantity and quality using MERIS data and the PROSAIL model. Remote Sens. Environ. 121, 415-425.

Thenkabail, P.S., Enclona, E.A., Ashton, M.S., Van der Meer, B., 2004. Accuracy assessments of hyperspectral waveband performance for vegetation analysis applications. Remote Sens. Environ. 91 (3-4), 354-376.

Tjuatja, S., Fung, A.K., Bredow, J.W., 1993. Optical Remote-Sensing of Air Pollutant an Analysis Using Wavelet Representation, Igarss'93: Better Understanding of Earth Environment, vols. I-IV, pp. 1953-1955.

Ullah, S., Skidmore, A.K., Naeem, M., Schlerf, M., 2012a. An accurate retrieval of leaf water content from mid to thermal infrared spectra using continuous wavelet analysis. Sci. Total Environ. 437, 145-152.

Ullah, S., Skidmore, A.K., Naeem, M., Schlerf, M., 2012b. Estimation of Leaf Water Content from Far Infrared (2.5-14 Mu M) Spectra Using Continuous Wavelet Analysis. In: 2012 IEEE International Geoscience and Remote Sensing Symposium (IGARSS): 4817-4820.

Ustin, S.L., Gitelson, A.A., Jacquemoud, S., Schaepman, M., Asner, G.P., Gamon, J.A., Zarco-Tejada, P., 2009. Retrieval of foliar information about plant pigment systems from high resolution spectroscopy. Remote Sens. Environ. 113, S67S77.

Verhoef, W., 1984. Light-scattering by leaf layers with application to canopy reflectance modeling - the sail model. Remote Sens. Environ. 16 (2), 125-141.

Vile, D., Garnier, É., Shipley, B., Laurent, G., Navas, M.-L., Roumet, C., Lavorel, S., et al. 2005. Specific leaf area and dry matter content estimate thickness in laminar leaves. Ann. Bot. 96 (6), 1129-1136.

Wang, M.C., Niu, X.F., Chen, S.B., Guo, P.J., Yang, Q., Wang, Z.J., 2014. Inversion of chlorophyll contents by use of hyperspectral CHRIS data based on radiative transfer model. In: 35th International Symposium on Remote Sensing of Environment (ISRSE35), 17.

Weiss, M., Baret, F., Myneni, R.B., Pragnere, A., Knyazikhin, Y., 2000. Investigation of a model inversion technique to estimate canopy biophysical variables from spectral and directional reflectance data. Agronomie 20 (1), 3-22.

Wilson, P.J., Thompson, K.E.N., Hodgson, J.G., 1999. Specific leaf area and leaf dry matter content as alternative predictors of plant strategies. New Phytol. 143 (1), $155-162$.

Wolf, A., Berry, J.A., Asner, G.P., 2010. Allometric constraints on sources of variability in multi-angle reflectance measurements. Remote Sens. Environ. 114 (6), 12051219.

Wright, I.J., Reich, P.B., Westoby, M., Ackerly, D.D., Baruch, Z., Bongers, F., CavenderBares, J., et al., 2004. The worldwide leaf economics spectrum. Nature 428 (6985), 821-827.

Yang, G.J., Zhao, C.J., Liu, Q., Huang, W.J., Wang, J.H., 2011. Inversion of a radiative transfer model for estimating forest LAI from multisource and multiangular optical remote sensing data. IEEE Trans. Geosci. Remote Sens. 49 (3), 988-1000.

Zhang, J.C., Yuan, L., Wang, J.H., Huang, W.J., Chen, L.P., Zhang, D.Y., 2012 Spectroscopic leaf level detection of powdery mildew for winter wheat using continuous wavelet analysis. J. Integ. Agr. 11 (9), 1474-1484. 